\title{
Dynamics Analysis of Mooring Near Space Airship with Nosecone Constraint
}

\author{
Geng Baogang ${ }^{*}$, Zhang Yongdong, Meng Xiaojun, Guo Kai, Ye Hu,Li Yunfei,Zhou Jianglong,Liu Yuan \\ Northwest Institute of Nuclear Technology, 710024 Xi'an, China
}

\begin{abstract}
The near space airships usually have a large volume. when the airship leave the boathouse, it is influenced by the near surface wind significantly, and the attitude of the airship will change, and the risk of the experiment will be increase. In this paper, the dynamics method is used to analyse the force in the mooring rope and the attitude of the airship with nosecone constraint. The kinetic equation is established. A typical near space airship is choose as an example. The RungeKutta method is used to solve the dynamic equation. According to calculation result, the change law of the force in the mooring rope and the attitude of the airship is given, which can provide reference for the near space airship experiment. For the airport in this paper, the force in the mooring rope near the tail in the windward side is bigger than the others. The stronger rope should be used in design.
\end{abstract}

\section{Introduction}

The near space airship flying in the bottom of the near space provide a long-duration running platform for many military and civilian applications[1-3]. Achieving the lift through buoyancy, the near space airship require mush less power than traditional aircraft. The near space airships can be usually tens of thousands to hundreds of thousands of cubic meters in size to provide enough lift in the near space. When the airship leave the boathouse, it is influenced by the near surface wind significantly, the attitude of the airship will change, and the risk of the experiment will increase. When the velocity of the wind increase, the mooring rope of the airship may break if the tension in the rope is at its maximum limit. The mooring tower which can fix the head of the airship to reduce the influence of the wind is used more and more in the near space airship experiment. The tension in the mooring rope is the key when the near space airship leave the boathouse, but there are less study on it[4-6].

In this paper, the dynamics method is used to analyse the force in the mooring rope and the attitude of the airship with nosecone constraint. The kinetic equation is established. A typical near space airship is choose as an example.

\section{Basic hypothesis}

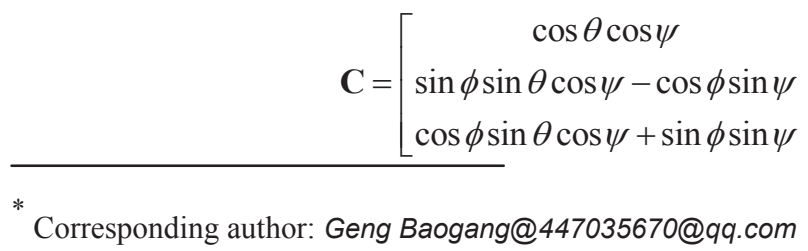

Make the following basic hypothesis before analysis:

(1) the near space airship is rigid body.

(2) The rotating angles of the airship along three axes are so small, and the changes in the length of the mooring rope are negligible.

(3) The weights of the mooring ropes are negligible.

\section{The coordinate system}

The airship moors in the nosecone with mooring tower and in the body with mooring rope. The coordinate system is shown in Fig.1. The inertial coordinate system $O X_{e} Y_{e} Z_{e}$ and the body-fitted coordinate system $O X_{b} Y_{b} Z_{b}$ is set up in the nosecone of the airship.

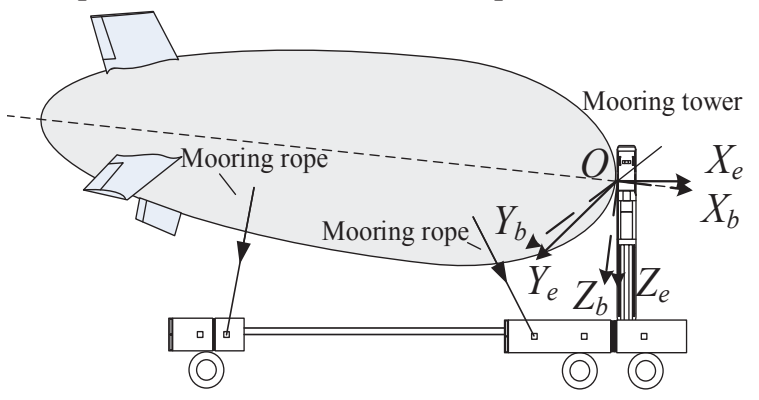

Fig.1. The coordinate system

The transform matrix is defined as:

$$
\left.\begin{array}{cc}
\cos \theta \sin \psi & -\sin \theta \\
\sin \phi \sin \theta \sin \psi+\cos \phi \cos \psi & \sin \phi \cos \theta \\
\cos \phi \sin \theta \sin \psi-\sin \phi \cos \psi & \cos \phi \cos \theta
\end{array}\right]
$$


Where $\phi, \theta, \psi$ is the rotating angle of the airship along $X_{e}, Y_{e}, Z_{e}$ axes, $\boldsymbol{\eta}=(\phi, \theta, \psi)^{T}$ is the Euler Angle.

$\boldsymbol{\omega}=(p, q, r)^{T}$ is the angle velocity in the body-fitted coordinate.

$$
\boldsymbol{p}=\mathrm{C}_{\omega} \boldsymbol{\omega}
$$

Where $\mathbf{C}_{\omega}$ is defined as:

$$
\boldsymbol{C}_{\omega}=\left[\begin{array}{ccc}
1 & \tan \theta \sin \phi & \tan \theta \cos \phi \\
0 & \cos \phi & -\sin \phi \\
0 & \sec \theta \sin \phi & \sec \theta \cos \phi
\end{array}\right]
$$

\section{The force analysis of the mooring rope}

When the near space airship leave the boathouse, it is influenced by the near surface wind. The forces on the airship include the gravity $\mathbf{G}$, the buoyancy $\mathbf{B}$, the aerodynamic force $\mathbf{P}$, and the forces in the mooring rope $\boldsymbol{T}_{i}$ ( $i$ is the number of the mooring rope). The kinetic equation is established in body-fitted coordinate.

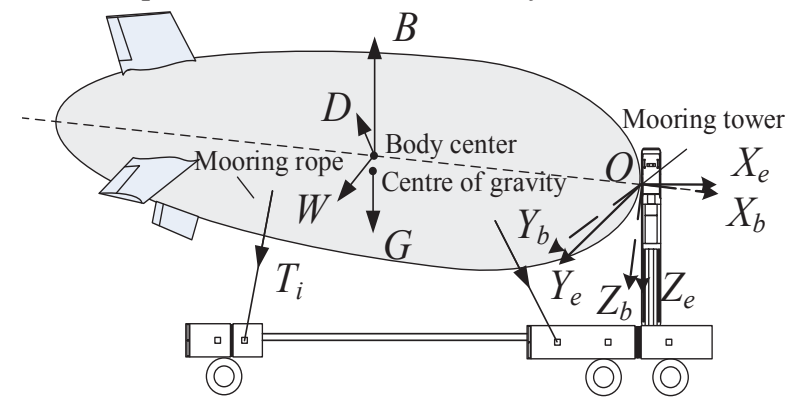

Fig.2. Force analysis of the airport

\subsection{The buoyancy and the gravity}

The buoyancy is defined as:

$$
\mathbf{B}=-\rho_{\text {air }} V \mathbf{g}
$$

Where $\rho_{\text {air }}$ is the density of the air; $V$ is the volume of the airship; $\mathbf{g}$ is the acceleration of gravity in body-fitted coordinate, $\mathbf{g}=\mathbf{C}(0,0,9.8)^{T}$.

The buoyancy moment is written as:

$$
\mathbf{M}_{B}=\mathbf{r}_{B} \times \mathbf{B}
$$

Where $\mathbf{r}_{B}$ is the body centred vector.

The gravity is defined as:

$$
\mathbf{G}=\left(m_{j}+\rho_{\text {air }} V_{\text {air }}+\rho_{h e} V_{h e}\right) \mathbf{g}
$$

Where $m_{j}$ the weight of the airship structure is, $V_{\text {air }}$ is the volume of the air in the airship, $V_{h e}$ is the volume of the helium in the airship, $\rho_{h e}$ is the density of the helium.

The gravity moment is written as:

$$
\mathbf{M}_{G}=\mathbf{r}_{G} \times \mathbf{G}
$$

Where $\mathbf{r}_{B}$ is the gravity centred vector..

\subsection{The tension in the mooring rope}

The elastic model of the rope is defined as:

$$
T_{i}= \begin{cases}k \frac{\mathrm{V} l_{i}}{l_{i}} & \mathrm{~V} l_{i}>0 \\ 0 & \mathrm{~V} l_{i} \leq 0\end{cases}
$$

Where $k$ is the elastic coefficient of the rope; $\mathrm{V}_{i}$ are the elongations of the mooring rope, $l_{i}$ are the initial lengths of the mooring rope. The directions of tensions are going from the mooring points on the airship to the mooring points of the transport vehicle.

Obviously, the tensions in the mooring ropes are affected by the space positions of the mooring points, and the tensions of the mooring ropes can be expressed as a function of the Euler Angle.

The coordinate of the mooring points in transfer vehicle are defined as $\mathbf{A}_{i}$, and the coordinate of the mooring points in airship are defined as $\mathbf{A}_{i}^{\prime}$, the initial length of the mooring rope are written as $l_{i}=\left\|\mathbf{A}_{i}^{\prime}-\mathbf{A}_{i}\right\|_{2}$, when the airship rotates, the $\mathbf{A}^{\prime}$ is invariant, and the $\mathbf{A}_{i}^{\prime}$ transforms into $\mathbf{A}_{i C}=\mathbf{C A}_{i}$, so the tensions in the mooring rope are written as:

$$
\mathbf{T}_{i}=-T_{i} \frac{\mathbf{A}_{i}^{\prime}-\mathbf{A}_{i C}}{l_{i C}}
$$

The forces moments in the mooring rope are written as:

$$
\mathbf{M}_{T}=\sum_{i=1}^{n} \mathbf{M}_{i}=\sum_{i=1}^{n} \mathbf{r}_{i} \times \mathbf{T}_{i}
$$

Where $\mathbf{r}_{i}$ are the coordinate vectors of the mooring points in the airship, $n$ is the number of the mooring rope.

\subsection{The aerodynamic force}

The aerodynamic force ${ }^{[7]}$ is defined as:

$$
\mathbf{P}=(X, Y, Z)^{T}
$$

where

$$
\begin{gathered}
X=\frac{1}{2} \rho_{\text {air }} v_{0}^{2} Q_{X} \\
Y=\frac{1}{2} \rho_{\text {air }} v_{0}^{2} Q_{Y} \\
Z=\frac{1}{2} \rho_{\text {air }} v_{0}^{2} Q_{Z}
\end{gathered}
$$

Where $X, Y, Z$ are the aerodynamic force on three axes, $v_{0}=v_{w}-\mathbf{r}_{B} \times \boldsymbol{\omega}$ is air velocity, $v_{w}$ is the velocity of the wind, $Q_{X}, Q_{Y}, Q_{Z}$ are aerodynamic parameters on three axes. Please see references [7] for the equations and parameters.

The aerodynamic force moment is written as:

$$
\mathbf{M}_{p}=\mathbf{r}_{B} \times \mathbf{P}
$$

\section{The kinetic equations}


Since the head of the airship is fixed with mooring tower, the translational equation is not necessary. The equation of motion is given as:

$$
\left(\mathbf{I}+\mathbf{I}_{a}\right) \boldsymbol{\&}+\boldsymbol{\omega} \times\left[\left(\mathbf{I}+\mathbf{I}_{a}\right) \boldsymbol{\omega}\right]=\mathbf{M}
$$

Where $\mathbf{I}$ is the rotational inertia of the airship, $\mathbf{I}_{a}$ is the added inertial.

$$
\mathbf{M}=\mathbf{M}_{G}+\mathbf{M}_{B}+\mathbf{M}_{T}+\mathbf{M}_{P}
$$

Combining Eqs.2 and 16, we obtain the coupled nonlinear equations:

$$
\left[\begin{array}{cc}
E & 0 \\
0 & I+I_{a}
\end{array}\right]\left[\begin{array}{c}
\phi \\
\omega
\end{array}\right]=\left[\begin{array}{c}
C_{\omega} \omega \\
M-\omega \times\left[\left(I+I_{a}\right) \omega\right]
\end{array}\right]
$$

\section{The example}

\subsection{The airship}

The example airship is shown in Fig.3. the length of the airship is $250 \mathrm{~m}$, the maximum diameter of the airship is $75 \mathrm{~m}$, and the weight of the airship is $45492 \mathrm{~kg}$. Helium ratio to total volume is 0.061 . The coordinate of gravity center is $(-115 \mathrm{~m}, 0 \mathrm{~m}, 1.66 \mathrm{~m})^{T}$, and the coordinate of the body center is $(-115 \mathrm{~m}, 0 \mathrm{~m}, 0 \mathrm{~m})^{T}$. The modulus of elasticity of mooring rope is $89 \mathrm{GPa}$, and the diameter of the mooring rope is $8 \mathrm{~mm}$.

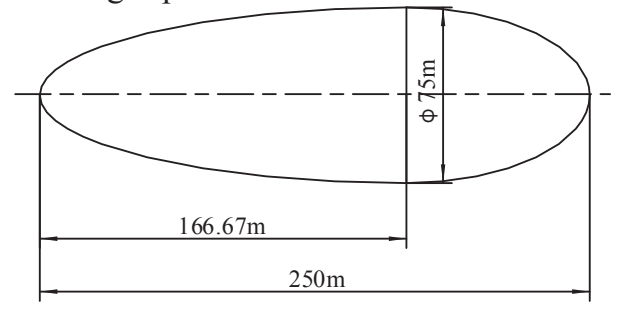

Fig.3. The airport for example

The mooring airship is shown in Fig.4, the height of the airship axis is $40 \mathrm{~m}$, the distance from mooring point in the transfer vehicle to the longitudinal symmetry plane of the airship is $60 \mathrm{~m}$.

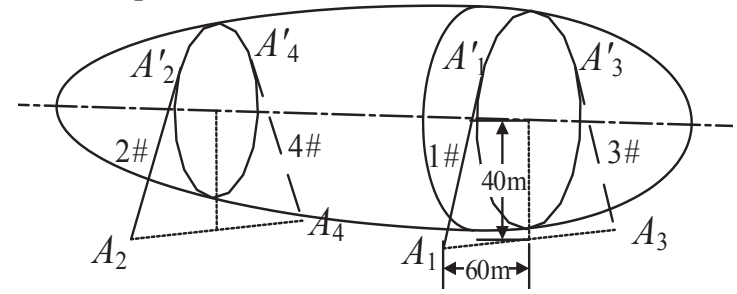

Fig.4. The mooring mode of the airport for example

\subsection{Calculation results}

The Runge-Kutta method is used to solve the dynamic equation. the result of the attitude changes of airship and The tensions in the mooring ropes under the influence of crosswind are shown in Fig.5-7.

According to the simulation results, with the increase of the crosswind velocity, the attitudes of the airship and the tensions of the mooring rope will change and tends to be stable. The time to reach the stable position will increase with the increase of the wind velocity. The variation of the tensions in the mooring rope with wind velocity can be divided into four stages
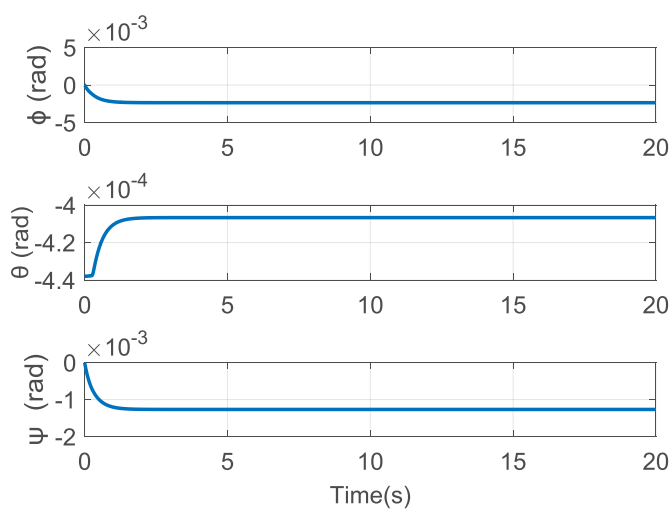

(a) attitude of the airship

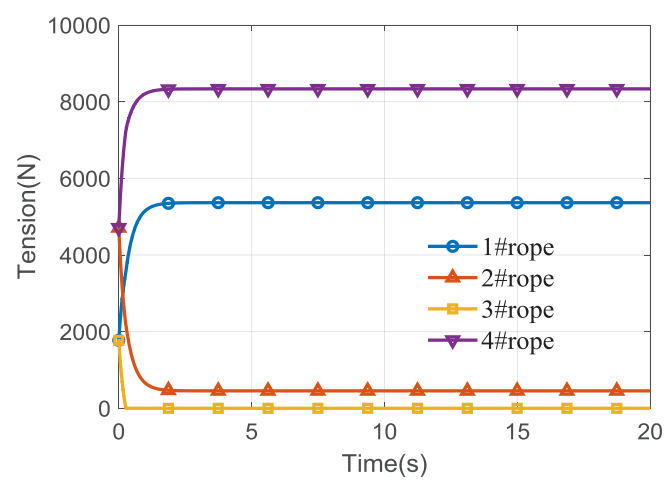

(b) The tension in the mooring ropes

Fig.5. The simulation result with wind velociry $1 \mathrm{~m} / \mathrm{s}$
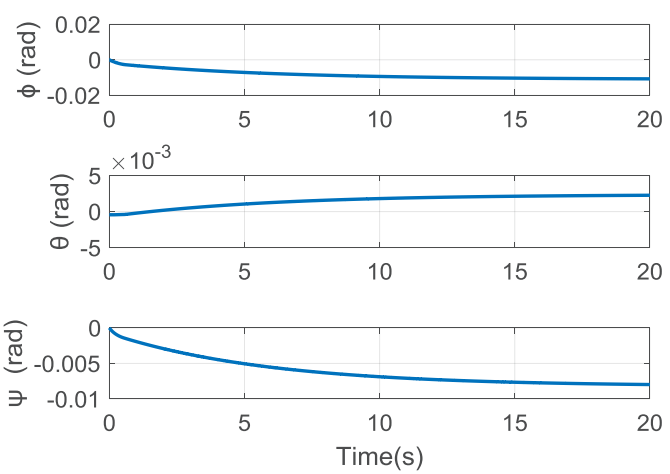

(a) attitude of the airship

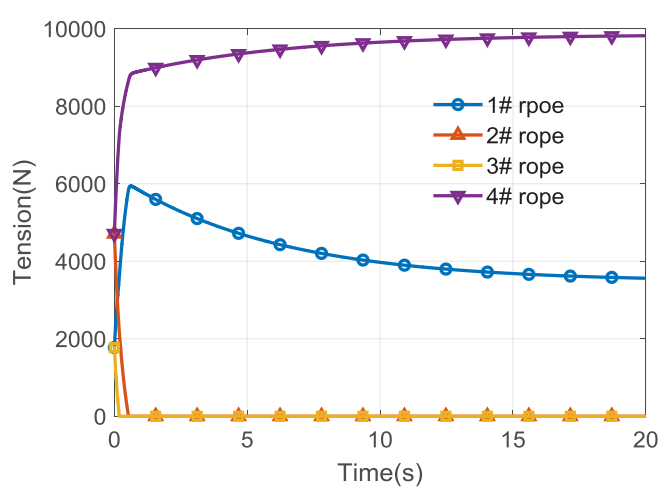

(b) The tension in the mooring ropes

Fig.6. The simulation result at wind velociry $1.2 \mathrm{~m} / \mathrm{s}$ 

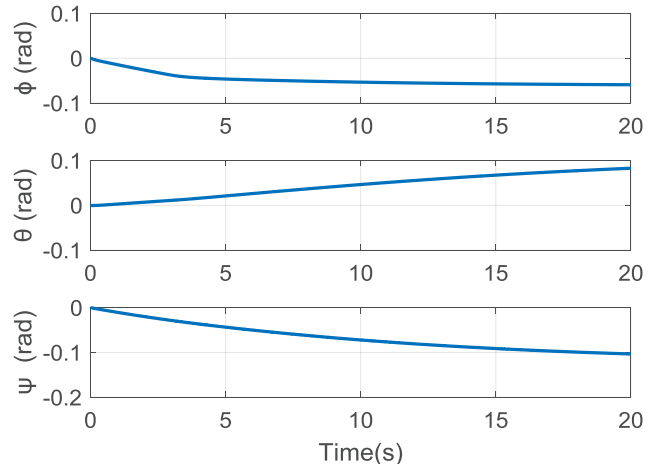

(a) attitude of the airship

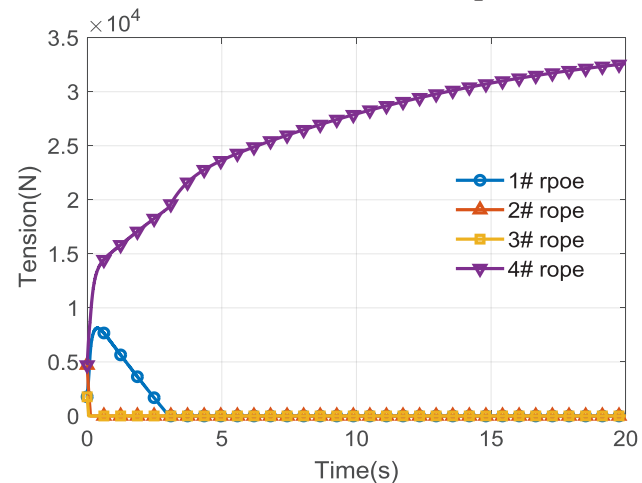

(b) The tension in the mooring ropes

Fig.7. The simulation result at wind velociry $3 \mathrm{~m} / \mathrm{s}$

(1) When $0 \mathrm{~m} / \mathrm{s}<v_{w}<0.8 \mathrm{~m} / \mathrm{s}$, all the four mooring ropes are under stress, the tension in $2 \#$ and $3 \#$ mooring rope decreases rapidly with time, and the tension in $1 \#$ and $4 \#$ mooring rope rises rapidly with time.

(2) With the increase of wind velocity, when $0.8 \mathrm{~m} / \mathrm{s}$ $\leqslant v_{w}<1.1 \mathrm{~m} / \mathrm{s}$, the tension in $2 \#$ and $3 \#$ mooring rope decreases rapidly, and the tension in $3 \#$ mooring rope decreases to 0 . The tension in $1 \#$ and $4 \#$ mooring ropes increases rapidly with time and tends to be stable gradually. A typical case is shown in Fig.5.

(3) As the wind velocity continues to increase, when $1.1 \mathrm{~m} / \mathrm{s} \leqslant v_{w}<1.5 \mathrm{~m} / \mathrm{s}$, the tension in the $3 \#$ and $2 \#$ mooring ropes drops rapidly and reduces to 0 . The tension in $1 \#$ mooring rope increased with the increase of wind velocity. When the tension in $3 \#$ and $2 \#$ mooring rope was 0 , it began to decrease. The tension in \#4 mooring rope increases rapidly with time. When the tension in $3 \#$ and $2 \#$ mooring rope is 0 , the increasing peed becomes slow, and tends to be stable gradually. A typical case is shown in Fig.6.

(4) When $v_{w} \geq 1.5 \mathrm{~m} / \mathrm{s}$, the tension in the $3 \#$ and $2 \#$ mooring ropes drops rapidly and reduces to 0 . With the increase of wind speed, the tension in $1 \#$ mooring rope presented a rapid trend at first. When the pull force of $3 \#$ and $2 \#$ mooring rope was 0 , it began to show a downward trend and gradually returned to 0 .The tension in $4 \#$ mooring rope increases rapidly with time, and tends to be stable gradually. A typical case is shown in Fig.7.

The variation of attitude angle and the tensions in the mooring ropes with the wind velocity after the airship reaches a steady state are shown in Fig.8. Table 1 shows the maximum tensions on the mooring ropes when the wind speed from $0 \mathrm{~m} / \mathrm{s}$ to $3 \mathrm{~m} / \mathrm{s}$, the wind velocities at the maximum tensions, and the wind velocities at the tensions on the mooring ropes drops to 0 . It can be seen that after the steady state is reached, the tension on the $3 \#$ and $2 \#$ mooring rope gradually decreases with the increase of wind velocity. When the wind velocity reaches $0.8 \mathrm{~m} / \mathrm{s}$ and $1.5 \mathrm{~m} / \mathrm{s}$, it decreases to 0 . The tension of $1 \#$ mooring rope increased with the increase of wind speed at first. When the tension of $3 \#$ and $2 \#$ mooring rope decreased to 0 , it began to decrease. When the wind speed reached $1.5 \mathrm{~m} / \mathrm{s}$, it decreased to 0 . The tension in $4 \#$ mooring rope increases with the increase of wind velocity.

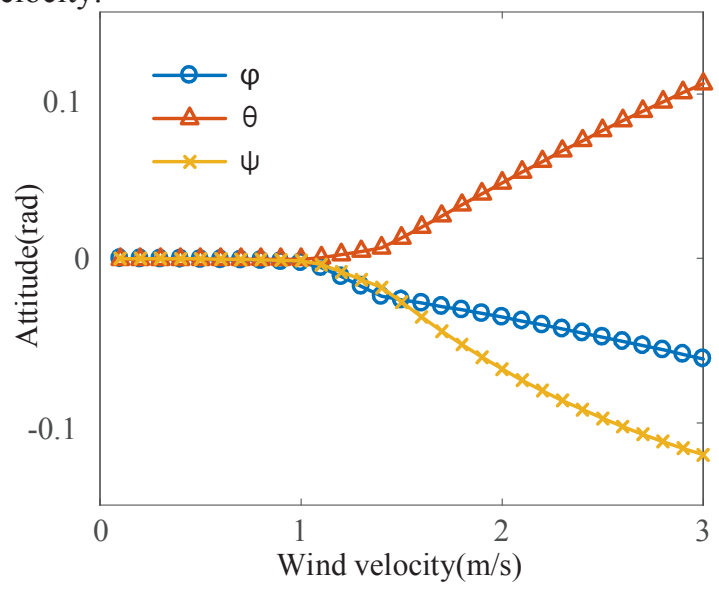

(a) attitude of the airship

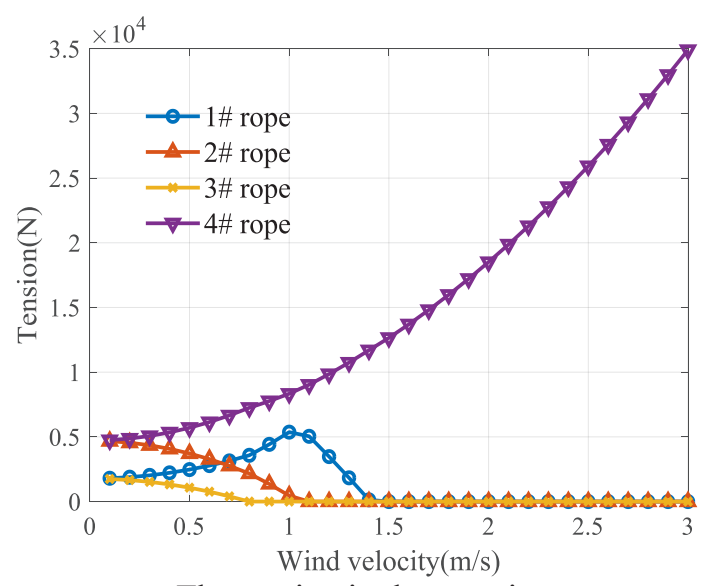

(b) The tension in the mooring ropes

Fig.8. The influence of wind when system was stable

Table 1. Tension in the rope.

\begin{tabular}{|c|c|c|c|}
\hline $\begin{array}{c}\text { Mooring } \\
\text { rope }\end{array}$ & $\begin{array}{c}\text { maximum } \\
\text { tension (N } \\
)\end{array}$ & $\begin{array}{c}\text { Wind velocity } \\
\text { at maximum } \\
\text { tension }(\mathbf{m} / \mathbf{s})\end{array}$ & $\begin{array}{c}\text { Wind velocity } \\
\text { at zero tension } \\
(\mathbf{m} / \mathbf{s})\end{array}$ \\
\hline $1 \#$ & 5365.74 & 1 & 1.5 \\
\hline $2 \#$ & 4669.80 & 0 & 1.1 \\
\hline $3 \#$ & 1745.49 & 0 & 0.8 \\
\hline $4 \#$ & 34902.62 & 3 & - \\
\hline
\end{tabular}

Therefore, under the influence of crosswind, the 4\# mooring rope at the tail of the windward side of the 
airship will bear more tension, which is the most vulnerable part of the 4 mooring ropes. For example, if the tensile strength of the mooring rope of the airship is $2 \mathrm{t}$, the rope will be break when the crosswind velocity is $2.2 \mathrm{~m} / \mathrm{s}$. Corresponding reinforcement measures should be adopted in the experiment design.

\section{Conclusion}

The dynamics method is used to analyzed the tensions in the mooring ropes and the attitude of the airship with nosecone constraint. Runge-Kutta numerical method is used to solve the equations. the results under the diffierent crosswind velocity are given, which can provide reference for near space airship experiment. Under the influence of crosswind, the mooring rope at the tail of wind ward side is under the maximum stress.

\section{References}

1. H. Stevens, Air. Force. Mag, 7, 36 (2005)

2. A.K. Gabriel. Airship Technology. (Cambridge University Press, 2012)

3. D. Zhao, D.X. Liu, K.W. Sun, et al. Acta. Aeronaut. Astronaut. Sin, 1, 45-56(2016)

4. T.H. Zhang, L.H. Jiang, D.H. Zhang, et al. Chin Space Sci Technol, 36,72-80(2016)

5. G.J. Wang. Xi'an: Xidian. Univ, 49-55,(2014)

6. Y.W, Wang, Y.H. Jia, Z.Q. Chen, et al. Spacecraft. Recov. Remot. Sens, 33, 93-99(2012)

7. B.M. Joseph, A.P. Michael. AIAA 3rd "Unmanned Unlimited” Tech. Conf, Works. Exhibit. 2-17(2004) 